\title{
Caffeine modulates phosphorylation of insulin receptor substrate- 1 and impairs insulin signal transduction in rat skeletal muscle
}

\section{$\operatorname{AUTHOR}(S)$ :}

Egawa, Tatsuro; Tsuda, Satoshi; Ma, Xiao; Hamada, Taku; Hayashi, Tatsuya

\section{CITATION:}

Egawa, Tatsuro ...[et al]. Caffeine modulates phosphorylation of insulin receptor substrate-1 and impairs insulin signal transduction in rat skeletal muscle. Journal of Applied Physiology 2011, 111(6): 1629-1636

\section{ISSUE DATE:}

2011-12-01

URL:

http://hdl.handle.net/2433/225033

\section{RIGHT:}

(c) 2011 The American Physiological Society; This is the accepted version of the article, which has been published in final form at http://doi.org/10.1152/japplphysiol.00249.2011; この論文は出版社版でありません。引用の際には出版社版をご確認ご利用ください。; This is not the published version. Please cite only the published version. 


\section{Caffeine modulates phosphorylation of insulin receptor substrate (IRS)-1 and impairs insulin signal transduction in rat skeletal muscle}

Tatsuro Egawa ${ }^{1}$, Satoshi Tsuda ${ }^{1}$, Xiao Ma ${ }^{1}$, Taku Hamada ${ }^{2}$, and Tatsuya Hayashi ${ }^{1}$

1 Laboratory of Sports and Exercise Medicine, Graduate School of Human and Environmental Studies, Kyoto University, Kyoto, Japan

2 Department of Health and Sports Management, Osaka University of Health and Sport Sciences, Osaka, Japan

Running head: EFFECTS OF CAFFEINE ON INSULIN SIGNALING

Address correspondence to:

Tatsuya Hayashi, M.D., Ph.D.

Laboratory of Sports and Exercise Medicine, Graduate School of Human and

Environmental Studies, Kyoto University, Yoshida-nihonmatsu-cho, Sakyo-ku, Kyoto, 606-8501, Japan

Telephone, Fax: +81-75-753-6640, E-mail: tatsuya@kuhp.kyoto-u.ac.jp 


\section{ABSTRACT}

Caffeine decreases insulin sensitivity and insulin-stimulated glucose transport in skeletal muscle; however, the precise mechanism responsible for this deleterious effect is not understood fully. We investigated the effects of incubation with caffeine on insulin signaling in rat epitrochlearis muscle. Caffeine ( $\geq 1 \mathrm{mM}, \geq 15 \mathrm{~min})$ suppressed insulin-stimulated insulin receptor substrate (IRS)-1 $\mathrm{Tyr}^{612}$ phosphorylation in a dose- and time-dependent manner. These responses were associated with inhibition of the insulin-stimulated phosphorylation of phosphatidylinositol-3 kinase (PI3K) $\mathrm{Tyr}^{458}$, Akt $\mathrm{Ser}^{473}$ and glycogen synthase kinase (GSK) $3 \beta \quad$ Ser $^{9}$, and with inhibition of insulin-stimulated 3-O-methyl-D-glucose (3MG) transport, but not with inhibition of the phosphorylation of insulin receptor $\beta \mathrm{Tyr}^{1158 / 62 / 63}$. Furthermore, caffeine enhanced phosphorylation of IRS-1 Ser ${ }^{307}$ and an IRS-1 Ser $^{307}$ kinase, inhibitor-кB kinase (IKK) $\alpha / \beta$ Ser $^{176 / 180}$. Blockade of IKK/IRS-1 Ser ${ }^{307}$ by caffeic acid ameliorated the caffeine-induced downregulation of IRS-1 $\mathrm{Tyr}^{612}$ phosphorylation and 3MG transport. Caffeine also increased the phosphorylation of IRS-1 Ser ${ }^{789}$ and an IRS-1 Ser $^{789}$ kinase, 5'AMP-activated protein kinase (AMPK). However, inhibition of IRS-1 Ser $^{789}$ and AMPK phosphorylation by dantrolene did not rescue the caffeine-induced downregulation of IRS-1 $\mathrm{Tyr}^{612}$ phosphorylation or 3MG transport. In addition, caffeine suppressed the phosphorylation of insulin-stimulated IRS-1 Ser ${ }^{636 / 639}$ and upstream kinases including the mammalian target of rapamycin (mTOR) and p70S6 kinase (p70S6K). Intravenous injection of caffeine at a physiological dose $(5 \mathrm{mg} / \mathrm{kg})$ in rats inhibited the phosphorylation of 
insulin-stimulated IRS-1 $\mathrm{Tyr}^{612}$ and Akt Ser ${ }^{473}$ in epitrochlearis muscle. Our results indicate that caffeine inhibits insulin signaling partly through the IKK/IRS-1 Ser ${ }^{307}$ pathway, via a $\mathrm{Ca}^{2+}$ - and AMPK-independent mechanism in skeletal muscle.

Keywords: serine phosphorylation, Akt, 5’AMP-activated protein kinase, p70 S6 kinase, inhibitor-кB kinase 


\section{INTRODUCTION}

Insulin-stimulated glucose transport by skeletal muscle plays an important role in the maintenance of whole-body glucose homeostasis (10). This biological response requires the tyrosine phosphorylation of the insulin receptor substrate (IRS)-1 and activation of its downstream effectors such as phosphatidylinositol-3 kinase (PI3K) and Akt. Maintaining proper responses of the IRS-PI3K-Akt pathway is crucial for normal insulin-mediated glucose metabolism in skeletal muscle. Many other signaling pathways can crosstalk with insulin metabolic signaling via the IRS-PI3K-Akt pathway, leading to reduced skeletal muscle responses to insulin and thereby contributing to systemic insulin resistance (2).

Caffeine (1,3,7-trimethylxanthine) is a xanthine alkaloid that has been implicated in the regulation of glucose metabolism in skeletal muscle. A number of studies have shown that acute caffeine stimulation ( $\geq 1 \mathrm{mM}$ ) increases glucose transport in the absence of insulin in incubated or perfused rodent skeletal muscles $(1,11,12,26$, 43), and 5'AMP-activated protein kinase (AMPK) has been considered part of the mechanism leading to the metabolic activation by caffeine $(1,11,12,26)$. On the other hand, caffeine seems to induce insulin resistance by inhibiting insulin signaling in skeletal muscle. Foukas et al. (14) have reported that $10 \mathrm{mM}$ caffeine directly inhibits PI3K activity in vitro and blocks the ability of insulin to stimulate Akt in incubated rat soleus muscle. More recently, Kolnes et al. (28) have reported that 10 mM caffeine blocks insulin-stimulated Akt phosphorylation and glucose transport in incubated rat skeletal muscles.

Tyrosine phosphorylation of IRS-1 by the insulin receptor (IR) allows binding and 
activation of PI3K and the subsequent activation of Akt $(2,6,18,37)$. On the other hand, serine phosphorylation of IRS-1 generally negates its ability to undergo tyrosine phosphorylation, thereby leading to an impairment in the insulin signaling cascade $(2,6,18,37)$. Several studies in human and rodent muscles have suggested the increased serine phosphorylation of IRS-1 in the insulin-resistant state $(33,45)$.

We hypothesized that the antagonistic effect of caffeine on insulin-stimulated Akt phosphorylation and glucose transport is caused by inhibiting IRS-1 tyrosine phosphorylation through increasing in IRS-1 serine phosphorylation. To test this hypothesis we investigated the effects of caffeine on insulin signaling molecules (IR, IRS-1, PI3K, and Akt) and glucose transport using an isolated rat skeletal muscle model. We also examined whether a physiological blood concentration of caffeine affects insulin-stimulated Akt phosphorylation and IRS-1 tyrosine phosphorylation in rat skeletal muscle. 


\section{MATERIALS AND METHODS}

Animals. Male Sprague-Dawley rats weighing 100-120 g were obtained from Shimizu Breeding Laboratories (Kyoto, Japan). Animals were housed in an animal room maintained at $22-24^{\circ} \mathrm{C}$ with a $12: 12$-h light-dark cycle and fed a standard laboratory diet (Certified Diet MF; Oriental Koubo, Tokyo, Japan) and water ad libitum. Rats were fasted overnight before the experiments and were randomly assigned to the experimental groups. All protocols for animal use and euthanasia followed the Guiding Principles for the Care and Use of Animals in the Field of Physiological Sciences (Physiological Society of Japan) in accordance with international guidelines, and were reviewed and approved by the Kyoto University Graduate School of Human and Environmental Studies and Kyoto University Radioisotope Research Center.

Muscle treatment in vitro. Muscles were treated as we described previously (11, 20, 39). Rats were killed by cervical dislocation without anesthesia, and the epitrochlearis muscles of each side were rapidly removed. Both ends of each muscle were tied with sutures (silk 3-0; Nitcho Kogyo, Tokyo, Japan) and the muscles were mounted on an incubation apparatus with a tension set to $0.5 \mathrm{~g}$. The buffers were continuously gassed with $95 \% \mathrm{O}_{2}-5 \% \mathrm{CO}_{2}$ and maintained at $37^{\circ} \mathrm{C}$. Muscles were preincubated in $7 \mathrm{~mL}$ of Krebs-Ringer bicarbonate buffer (KRB) (117 mM NaCl, 4.7

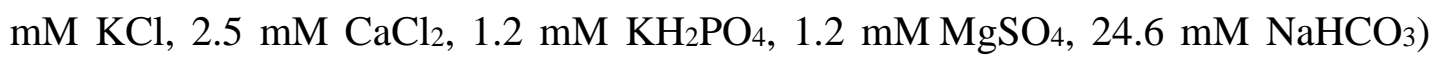
containing $2 \mathrm{mM}$ pyruvate (KRBP) for $40 \mathrm{~min}$. For the dose- and time-dependent effects of caffeine, muscles were then randomly assigned to incubation in $7 \mathrm{~mL}$ of 
fresh buffer in the absence or presence of $0.1-3 \mathrm{mM}$ caffeine for $15 \mathrm{~min}$, or in $7 \mathrm{~mL}$ of fresh buffer in the absence or presence of $3 \mathrm{mM}$ caffeine for up to $60 \mathrm{~min}$, respectively. In other experiments, muscles were incubated in the absence or presence of $3 \mathrm{mM}$ caffeine for $15 \mathrm{~min}$. Muscles were then incubated in $7 \mathrm{ml}$ of fresh buffer with $1 \mu \mathrm{M}$ insulin in the absence or presence of caffeine for $15 \mathrm{~min}$. Control samples were identically preincubated and incubated without caffeine or insulin stimulation. In some experiments, caffeic acid (Sigma, St. Louis, MO) or dantrolene (Sigma) was added during the preincubation and incubation periods to inhibit inhibitor- $\kappa \mathrm{B}$ kinase (IKK) (32) and AMPK (26), respectively. The maximal concentration of vehicle (DMSO) for dantrolene was $0.1 \%$, which did not affect any assay. The muscles were then used for the measurement of glucose transport, or immediately frozen in liquid nitrogen and subsequently analyzed for western blot.

Muscle treatment in vivo. Muscles were treated as we described previously (12). Caffeine was dissolved in saline and injected into the tail vein without anesthesia at $5 \mathrm{mg} / \mathrm{kg}$ body weight. The injection volume was $1 \mathrm{ml} / \mathrm{kg}$ body weight. Saline was injected as a control. The rat was temporarily restricted in a Ballman's cage during injection. Sixty minutes after caffeine or saline injection, rats were anaesthetized with intraperitoneal administration of pentobarbital sodium (50 mg/kg body weight), and then insulin (100 mU/kg body weight) or saline was injected intravenously. One min after injection epitrochlearis muscle was rapidly dissected and immediately frozen in liquid nitrogen.

Western blot analysis. Sample preparation and western blot analysis was performed 
as we described previously $(11,24,39)$. Muscles were homogenized in ice-cold lysis buffer (1:40 wt/vol) containing $20 \mathrm{mM}$ Tris $\cdot \mathrm{HCl}(\mathrm{pH} 7.4), 1 \%$ Triton $\mathrm{X}, 50 \mathrm{mM}$ $\mathrm{NaCl}, 250 \mathrm{mM}$ sucrose, $50 \mathrm{mM} \mathrm{NaF}, 5 \mathrm{mM}$ sodium pyrophosphate, $2 \mathrm{mM}$ dithiothreitol, $4 \mathrm{mg} / \mathrm{L}$ leupeptin, $50 \mathrm{mg} / \mathrm{L}$ trypsin inhibitor, $0.1 \mathrm{mM}$ benzamidine, 1 $\mathrm{mM} \mathrm{Na} \mathrm{VO}_{4}$, and $0.5 \mathrm{mM}$ phenylmethylsulfonyl fluoride and centrifuged at 16,000 $g$ for 40 min at $4^{\circ} \mathrm{C}$. Lysates were solubilized in Laemmli's sample buffer containing mercaptoethanol and boiled. The samples (10 $\mu \mathrm{g}$ of protein) were separated by SDS-PAGE using 7.5\% polyacrylamide gel. Proteins were then transferred to polyvinylidene difluoride membranes (PolyScreen; PerkinElmer, Wellesley, MA) at $100 \mathrm{~V}$ for $1 \mathrm{~h}$. Membranes were blocked for $1 \mathrm{~h}$ at room temperature in TBS-T (TBS with $0.1 \%$ Tween 20 ) containing $5 \%$ nonfat dry milk and were then incubated over night at $4^{\circ} \mathrm{C}$ with primary antibody [IR $\mathrm{Tyr}^{1158 / 1162 / 1163}$, IRS-1 $\mathrm{Tyr}^{612}$ (Invitrogen, Carlsbad, CA), IR, IRS-1 Ser ${ }^{636 / 639}$, mammalian target of rapamycin (mTOR) Ser ${ }^{2448}$, mTOR, p70 S6 kinase (p70S6K) Thr ${ }^{389}$, p70S6K, IKK $\alpha / \beta$ Ser $^{176 / 180}$, IKK $\alpha$, IKK $\beta$, c-Jun N-terminal kinase (JNK) Thr ${ }^{183} / \mathrm{Tyr}^{185}$, JNK, p44/42 MAPK (ERK) Thr ${ }^{202} / \mathrm{Tyr}^{204}$, p44/42 MAPK, p38 MAPK $\mathrm{Thr}^{180} / \mathrm{Tyr}^{182}$, p38 MAPK, PI3K p85 $\mathrm{Tyr}^{458}$, Akt Ser ${ }^{473}$, Akt, glycogen synthase kinase (GSK) $3 \beta$ Ser $^{9}$, GSK3 $\beta$, AMPK $\mathrm{Thr}^{172}$, AMPKa, acetyl CoA carboxylase (ACC) (Cell Signaling Technology, Danvers, MA), PI3K p85, ACC Ser ${ }^{79}$ (Millipore, Billerica, MA)]. The membranes were then washed and incubated for $1 \mathrm{~h}$ at room temperature with anti-rabbit IgG (GE Healthcare, Buckinghamshire, UK). To immunoprecipitate the IRS-1, an aliquot of supernatant was prepared as described above (100 $\mu \mathrm{g}$ of protein) and incubated with anti-IRS-1 (Millipore) and protein A-Sepharose CL4B beads (GE Healthcare) overnight with end-over-end rotation at $4{ }^{\circ} \mathrm{C}$. The immunoprecipitate was washed 
three times in the lysis buffer, and then centrifuged at $4000 \times \mathrm{g}$ for $30 \mathrm{~s}$ at $4{ }^{\circ} \mathrm{C}$. The supernatant was removed, and the beads were mixed with the sample buffer and boiled. The denatured proteins were separated on a $7.5 \%$ polyacrylamide gel and then transferred as described above. The membrane was blocked with TBS-T containing 5\% nonfat dry milk for $1 \mathrm{~h}$ at room temperature, and then incubated with anti-IRS-1 or anti- IRS-1 Ser ${ }^{307}$ (Cell Signaling Technology). The membranes were then washed, incubated for $1 \mathrm{~h}$ at room temperature with Rabbit TrueBlot IgG (eBioscience, San Diego, CA). Protein signals were detected with enhanced chemiluminescence reagents according to the manufacturer's instructions (GE Healthcare) and an ImageCapture G3 (Liponics, Tokyo, Japan). The intensity of the signals was quantified using ImageJ (3). The mean intensity of control samples in each membrane was used as reference for controlling gel-to-gel variation. Equal protein loading and transfer was confirmed by Coomassie brilliant blue staining of the membranes.

3-O-methyl-D-glucose (3MG) transport. 3MG transport assay was performed as we described previously $(11,20,39)$. To measure 3MG transport after caffeine or insulin incubation, muscles were transferred to $2 \mathrm{~mL}$ of KRB containing $1 \mathrm{mM}\left[{ }^{3} \mathrm{H}\right] 3-\mathrm{MG}$ (1.5 $\mu \mathrm{Ci} / \mathrm{mL}$ ) (American Radiolabeled Chemicals, St. Louis, MO) and $7 \mathrm{mM}$ D-[1-14C] mannitol (0.3 $\mu \mathrm{Ci} / \mathrm{mL})$ (American Radiolabeled Chemicals, St. Louis, MO) at $30^{\circ} \mathrm{C}$ and further incubated for $10 \mathrm{~min}$. The muscles were then blotted onto filter paper, trimmed, frozen in liquid nitrogen, and stored at $-80^{\circ} \mathrm{C}$. Each frozen muscle was weighed and processed by incubating them in $300 \mu \mathrm{l}$ of $1 \mathrm{M} \mathrm{NaOH}$ at $80^{\circ} \mathrm{C}$ for $10 \mathrm{~min}$. Digestates were neutralized with $300 \mu \mathrm{l}$ of $1 \mathrm{M} \mathrm{HCl}$, and particulates were 
precipitated by centrifugation at 20,000 $\mathrm{g}$ for $2 \mathrm{~min}$. Radioactivity in aliquots of the digested protein was determined by liquid scintillation counting for dual labels, and the extracellular and intracellular spaces were calculated (44).

Statistical analysis. Results are presented as means \pm SE. Multiple means were compared by ANOVA followed by post hoc comparison with Dunnet’s or Tukey‘s test as appropriate. Differences between groups were considered statistically significant at $\mathrm{P}<0.05$. 


\section{RESULTS}

Caffeine decreased basal and insulin-stimulated IRS-1 Tyr ${ }^{612}$ phosphorylation in a dose- and time-dependent manner. To examine the state of tyrosine phosphorylation of IRS-1, we measured the degree of phosphorylation of IRS-1 $\mathrm{Tyr}^{612}$ - a binding site for the p85 subunit of PI3K and important for the full activation of PI3K in response to insulin (13) —in muscle incubated with caffeine at various concentrations $(0,0.01,0.1,1$ and $3 \mathrm{mM})$ and for various times $(0,5,15,30$ and $60 \mathrm{~min}$ ). This dose-response study showed that preincubation with caffeine at 1 and $3 \mathrm{mM}$ lowered insulin-stimulated IRS-1 $\mathrm{Tyr}^{612}$ phosphorylation significantly more than in muscle incubated with insulin alone (Fig. 1A). Caffeine (3 mM) also decreased basal IRS-1 $\operatorname{Tyr}^{612}$ phosphorylation (Fig. 1A). The time-course study revealed that insulin-stimulated IRS-1 $\mathrm{Tyr}^{612}$ phosphorylation decreased after preincubation with caffeine for over 15 min (Fig. 1B).

Caffeine did not change IR $\beta$ Tyr ${ }^{1158 / 62 / 63}$ phosphorylation. We performed western blot analysis using an anti-IR $\beta$ antibody that recognizes phosphorylated $\mathrm{Tyr}^{1158 / 1162 / 1163}$ to identify whether caffeine affects tyrosine phosphorylation of IR $\beta$. Tyrosine phosphorylation of IR $\beta$ was clearly increased by insulin stimulation, whether or not the muscle was incubated with caffeine (Fig. 2A). Caffeine did not affect the basal tyrosine phosphorylation state of IR $\beta$ (Fig. 2A).

Caffeine blocked basal and insulin-stimulated PI3K p85 Tyr ${ }^{458}$ and Akt Ser ${ }^{473}$ phosphorylation and inhibited insulin-stimulated glucose transport. To determine 
the activation state of PI3K and Akt, we performed western blot analysis with a phosphospecific anti-PI3K p85 antibody that recognizes phosphorylated $\mathrm{Tyr}^{458}$, an indicator of PI3K activation (29), and anti-Akt antibody that recognizes phosphorylated Ser ${ }^{473}$. Insulin significantly increased PI3K and Akt phosphorylation, but caffeine (3 mM, $15 \mathrm{~min}$ ) blocked basal and insulin-stimulated PI3K phosphorylation (Fig. 2B) and Akt phosphorylation (Fig. 2C). GSK-3 $\beta$ Ser$^{9}$, a downstream target of Akt, also displayed a pattern similar to that for Akt phosphorylation (Fig. 2D). Next, we examined whether caffeine would affect basal and insulin-stimulated glucose transport in skeletal muscle. Caffeine increased 3 MG transport activity by 2.2-fold compared with basal levels in the absence of insulin (Fig. 2E), as observed in our previous studies $(11,12)$. Insulin increased the activity by 5.3-fold, but in muscles incubated with caffeine the rate of insulin-stimulated 3 MG transport activity was decreased significantly compared with muscles incubated with insulin alone (Fig. 2E).

Caffeine-induced IRS-1 Ser Snd $^{307}$ and $\mathrm{IK} / \beta$ Ser ${ }^{176 / 180}$ phosphorylation were associated with inhibition of insulin signaling and insulin-stimulated glucose transport. To examine whether caffeine affects the serine phosphorylation of IRS-1, we performed western blot analysis using an anti-IRS-1 antibody that recognizes phosphorylated $\mathrm{Ser}^{307}$-a molecular indicator of insulin resistance $(6,18)$. Caffeine significantly increased IRS-1 $\operatorname{Ser}^{307}$ phosphorylation in both basal and insulin-stimulated conditions (Fig. 3A). IKK is a mediator of insulin resistance through IRS-1 Ser ${ }^{307}$ phosphorylation $(9,16)$, and other stress related kinases such as JNK, ERK, and p38 MAPK have also been shown to promote $\mathrm{Ser}^{307}$ 
phosphorylation $(4,7-9,22)$. Therefore, we next evaluated the effects of caffeine on the phosphorylation states of IKK $\alpha / \beta \quad \mathrm{Ser}^{176 / 180}$, JNK $\mathrm{Thr}^{183} / \mathrm{Tyr}^{185}$, ERK $\mathrm{Thr}^{202} / \mathrm{Tyr}^{204}$ and p38 MAPK $\mathrm{Thr}^{180} / \mathrm{Tyr}^{182}$. Caffeine clearly increased IKK $\alpha / \beta$ Ser ${ }^{176 / 180}$ phosphorylation in both basal and insulin-stimulated conditions (Fig. 3B), whereas phosphorylation of JNK, ERK, and p38 MAPK were not affected by caffeine (Fig. 3C-E). The cancelling of the caffeine-induced phosphorylation of IRS-1 $\operatorname{Ser}^{307}$ (Fig. 4A) and IKK $\alpha / \beta$ Ser $^{176 / 180}$ (Fig. 4B) by $5 \mathrm{mM}$ caffeic acid (32) was associated with significant reductions in the inhibitory effects of caffeine on insulin-stimulated IRS-1 Tyr ${ }^{612}$ (Fig. 4C) and Akt Ser ${ }^{473}$ (Fig. 4D) phosphorylation, and 3MG transport (Fig. 4E).

Caffeine-induced IRS-1 Ser ${ }^{789}$ and AMPK Thr ${ }^{172}$ phosphorylation were not paralleled by the inhibition of insulin signaling or insulin-stimulated glucose transport. Ser ${ }^{789}$ was shown to negatively regulate insulin signal transduction and this site seems to be a target for AMPK (41). Thus, we examined the effect of caffeine on the phosphorylation state of IRS-1 Ser ${ }^{789}$, AMPK Thr ${ }^{172}$, and ACC Ser ${ }^{79}$, a well-characterized substrate of AMPK. The phosphorylation state of $\operatorname{Ser}^{789}$ was significantly enhanced by caffeine in both the presence and absence of insulin (Fig. 5A). Phosphorylation of AMPK Thr ${ }^{172}$ (Fig. 5B) and ACC $\operatorname{Ser}^{79}$ (Fig. 5C) were increased by caffeine, as observed in our previous studies $(11,12)$, and displayed a pattern similar to that of IRS-1 Ser ${ }^{789}$ phosphorylation (Fig. 5A). Cancelling the stimulatory effect of caffeine on the phosphorylation of IRS-1 Ser ${ }^{789}$ (Fig. 6A) and AMPK $\operatorname{Thr}^{172}$ (Fig. 6B) by the $\mathrm{Ca}^{2+}$ release inhibitor dantrolene $(10 \mu \mathrm{M})$ did not rescue the inhibitory effects of caffeine on insulin-stimulated IRS-1 Tyr ${ }^{612}$ (Fig. 6C) 
and Akt Ser ${ }^{473}$ (Fig. 6D) phosphorylation and 3MG transport (Fig. 6E).

Caffeine decreased insulin-stimulated IRS-1 Ser ${ }^{636 / 639}$, mTOR Ser ${ }^{2448}$, and p70S6K Thr ${ }^{389}$ phosphorylation. We performed western blot analysis using an anti-IRS-1 antibody that recognizes phosphorylated Ser ${ }^{636 / 639}$ —a residue involved in insulin resistance $(40,42)$. Caffeine did not change basal Ser ${ }^{636 / 639}$ phosphorylation: however, insulin-stimulated Ser ${ }^{636 / 639}$ phosphorylation was significantly suppressed in the muscle incubated with caffeine (Fig. 7A). Next, to determine whether caffeine might modulate mTOR/p70S6K transduction, which is accompanied by a corresponding increase in IRS-1 phosphorylation of $\operatorname{Ser}^{636 / 639}$ (40, 42), we performed western blot analysis using an anti-mTOR antibody that recognizes phosphorylated $\mathrm{Ser}^{2448}$ and anti-p70S6K antibody that recognizes phosphorylated $\mathrm{Thr}^{389}$. Consistent with the inhibitory effect of caffeine on insulin-stimulated IRS-1 Ser ${ }^{636 / 639}$ phosphorylation, the stimulatory effect of insulin on mTOR and p70S6K phosphorylation was blocked by caffeine (Figs. 7B and 7C). Caffeine alone decreased basal mTOR phosphorylation but not p70S6K phosphorylation (Figs. 7B and 7C).

In vivo caffeine treatment inhibited insulin signaling in skeletal muscle. To determine whether a physiological blood concentration of caffeine affects insulin signaling, the phosphorylation of IRS- $1 \mathrm{Tyr}^{612}$ and Akt $\mathrm{Ser}^{473}$ in muscles dissected $60 \mathrm{~min}$ after intravenous injection of $5 \mathrm{mg} / \mathrm{kg}$ caffeine was estimated. In humans, following an ingestion of caffeine in amounts corresponding to 2-3 cups of coffee, plasma caffeine levels reach 20-50 $\mu \mathrm{M}$ (15). Habitual coffee consumers (7 cups/day) 
show a peak plasma caffeine concentration of about $50 \mu \mathrm{M}$, with a mean $24 \mathrm{~h}$ plasma level of about $25 \mu \mathrm{M}$ (31). We showed previously that administration of 5 $\mathrm{mg} / \mathrm{kg}$ caffeine into the tail vein of the rats increases the blood concentration of caffeine to $50 \mu \mathrm{M} 60$ min after the injection (12). Caffeine significantly suppressed basal and insulin-stimulated phosphorylation of IRS-1 $\mathrm{Tyr}^{612}$ (Fig. 8A) and Akt $\operatorname{Ser}^{473}$ (Fig. 8B). 


\section{DISCUSSION}

The present study is the first report to show that caffeine inhibits basal and insulin-stimulated IRS-1 tyrosine phosphorylation (Fig. 1) and PI3K phosphorylation (Fig. 2B), but not IR $\beta$ tyrosine phosphorylation (Fig. 2A) in skeletal muscle. These inhibitory effects were also confirmed by in vivo caffeine treatment (Fig. 8). Our results suggest that caffeine affects the functions of IRS-1 either directly and/or through molecules other than IR $\beta$, and impairs PI3K and Akt activity and glucose transport in skeletal muscle.

Ser $^{307}$ of IRS-1 is located close to the phosphotyrosine-binding domain of IRS-1 (36) and its phosphorylation has been demonstrated to inhibit insulin-stimulated tyrosine phosphorylation of IRS-1 and subsequent activation of PI3K (4, 22). We found here that caffeine upregulated the phosphorylation state of IRS-1 Ser ${ }^{307}$ (Fig. 3A) and enhanced both the basal and insulin-stimulated phosphorylation of IKK (Fig. 3B) but not of JNK, ERK or p38 MAPK (Fig. 3C-E). In addition, blockade of the IKK/NF- $\mathrm{B}$ pathway by caffeic acid ameliorated the caffeine-induced inhibition of insulin signaling and insulin-stimulated glucose transport (Fig. 4). IKK is the master regulator of NF- $\kappa \mathrm{B}$ activation in response to inflammatory stimuli, and the IKK/NF- $\mathrm{B}$ pathway is a core mechanism that conveys insulin resistance in peripheral tissues $(35,37)$. Our results suggest that the inhibitory effect of caffeine on insulin signaling occurs through IKK-induced IRS-1 Ser ${ }^{307}$ phosphorylation.

We also found that caffeine increased both basal and insulin-stimulated IRS-1 Ser $^{789}$ phosphorylation (Fig. 5A) with similar increases in AMPK and ACC phosphorylation (Figs. 5B and 5C). Ser ${ }^{789}$ of IRS-1 was shown to be phosphorylated 
in vitro by $\mathrm{AMPK}$ and to promote insulin signaling in muscle $\mathrm{C}_{2} \mathrm{C}_{12}$ cells (25). By contrast, some studies have proposed an association between $\operatorname{Ser}^{789}$ phosphorylation and insulin resistance $(23,34,41)$. For example, Tzatsos et al. (41) showed that energy depletion and oxidative stress stimulated AMPK and IRS-1 Ser ${ }^{789}$ phosphorylation and suppressed insulin-stimulated IRS-1-associated PI3K activity and Akt phosphorylation in L6 myoblasts. In the present study, we found that $\mathrm{Ca}^{2+}$ release blocker dantrolene, which has been reported to inhibit caffeine-induced AMPK activation in mouse skeletal muscle (26), suppressed both caffeine-induced AMPK phosphorylation and IRS-1 Ser ${ }^{789}$ phosphorylation, but did not rescue IRS-1 tyrosine phosphorylation, Akt phosphorylation or insulin-stimulated glucose transport (Fig. 6). Similarly, Kolnes et al. (28) demonstrated recently that dantrolene does not rescue caffeine-mediated blockade of insulin-stimulated Akt phosphorylation and glucose transport in incubated rat skeletal muscles. These observations are not surprising because muscle contraction, a physiological stimulator of both $\mathrm{Ca}^{2+}$ release and AMPK activity, does not induce insulin resistance in skeletal muscle. Taken together, these data suggest that caffeine inhibits insulin signaling via $\mathrm{Ca}^{2+}$-independent and AMPK/IRS-1 $\mathrm{Ser}^{789}$-independent mechanisms in skeletal muscle.

The Ser ${ }^{636 / 639}$ of IRS-1 is also a site involved in insulin resistance and mTOR/p70S6K could be responsible for this phosphorylation $(40,42)$. We have reported that the branched-chain amino acid leucine inhibits insulin-stimulated glucose transport in skeletal muscle and that this inhibition is associated with mTOR/p70S6K-induced Ser ${ }^{636 / 639}$ phosphorylation of IRS-1 (24). In the present study, contrary to our expectations, caffeine decreased insulin-stimulated IRS-1 
Ser ${ }^{636 / 639}$ phosphorylation (Fig. 7A) and mTOR and p70S6K phosphorylation (Fig. 7B and 7C). Thus, the mTOR/p70S6K/IRS-1 Ser S36/639 $^{6}$ cascade might not be an important regulator of the caffeine-mediated reduction of insulin signaling. It is notable that insulin stimulation significantly increased Ser ${ }^{636 / 639}$ phosphorylation of IRS-1 (Fig. 7A), as reported in previous studies (21, 42) and one of our studies (24). Although the actual role of the p70S6K/IRS-1 Ser (36/639 $^{6}$ upregulation by insulin has not been clarified, it has been assumed that a feedback mechanism is evoked simultaneously to regulate the activation of insulin signaling including the PI3K/Akt pathway $(19,42)$.

A number of reports have documented that acute caffeine administration decreases whole-body glucose tolerance and insulin sensitivity in humans (5, 17, 27, 30, 38). In particular, acute caffeine ingestion reduces insulin-stimulated glucose disposal during a hyperinsulinemic clamp (5, 17, 30), indicating that caffeine-mediated insulin resistance occurs in skeletal muscle (10). Thong et al. (38) showed that caffeine ingestion impairs skeletal muscle glucose uptake in human skeletal muscle during a hyperinsulinemic clamp. However, Thong et al. (38) did not detect any alterations in insulin receptor tyrosine kinase activity, PI3K activity, or Akt phosphorylation in biopsy samples from caffeine-treated muscle. By contrast, our results show that a physiological concentration of caffeine in live rats blocks IRS-1 tyrosine phosphorylation and Akt phosphorylation in skeletal muscle (Fig. 8). Although we have no rational explanation for this difference, we believe that the present study gives new insights into how caffeine modulates insulin actions including glucose transport in vivo.

In summary, we demonstrated that caffeine decreases insulin-stimulated 
phosphorylation of IRS-1 Tyr ${ }^{612}$, PI3K Tyr ${ }^{458}$, Akt Ser ${ }^{473}$ and GSK-3 $\beta$ Ser $^{9}$ and 3MG transport without affecting IR $\beta$ tyrosine phosphorylation in rat skeletal muscle. We also found that caffeine promotes the phosphorylation of IRS-1 at $\operatorname{Ser}^{307}$ with corresponding increases in IKK phosphorylation, and that suppressing the IKK/IRS-1 Ser ${ }^{307}$ cascade by caffeic acid ameliorates caffeine-induced insulin resistance. Caffeine also increased IRS-1 $\operatorname{Ser}^{789}$ and AMPK phosphorylation, but inhibition of IRS-1 Ser ${ }^{789}$ and AMPK phosphorylation by dantrolene did not rescue the caffeine-induced insulin resistance. We propose that caffeine acutely inhibits insulin signaling at least in part via the IKK-induced IRS-1 Ser ${ }^{307}$ phosphorylation independently of $\mathrm{Ca}^{2+}$ release or AMPK activation in skeletal muscle. 


\section{ACKNOWLEDGMENTS}

We thank Nobumasa Iwanaka for technical advice. We also thank Department of Medicine and Clinical Science Kyoto University Graduate School of Medicine, Radioisotope Research Center of Kyoto University, and Kyoto University Research Center for Low Temperature and Materials Sciences for instrumental support. 


\section{GRANTS}

Tatsuro Egawa was supported by a Research Fellowship of the Japan Society for the Promotion of Science for Young Scientists. Tatsuya Hayashi was supported by research grants from the Japan Society for the Promotion of Science (20500576), the All Japan Coffee Association, Nestle Nutrition Council Japan, and Japan Vascular Disease Research Foundation. Taku Hamada was supported by research grants from the Japan Society for the Promotion of Science (22500616) and the All Japan Coffee Association. 


\section{DISCLOSURES}

The authors state that there are no conflicts of interest. 


\section{REFERENCES}

1. Abbott MJ, Edelman AM, and Turcotte LP. CaMKK is an upstream signal of AMP-activated protein kinase in regulation of substrate metabolism in contracting skeletal muscle. Am J Physiol Regul Integr Comp Physiol 297: R1724-1732, 2009.

2. Abdul-Ghani MA, and DeFronzo RA. Pathogenesis of insulin resistance in skeletal muscle. J Biomed Biotechnol 2010: 476279, 2010.

3. Abramoff MD, Magelhaes PJ, and Ram SJ. Image Processing with ImageJ. Biophotonics International 11: 36-42, 2004.

4. Aguirre V, Werner ED, Giraud J, Lee YH, Shoelson SE, and White MF. Phosphorylation of Ser ${ }^{307}$ in insulin receptor substrate-1 blocks interactions with the insulin receptor and inhibits insulin action. J Biol Chem 277: 1531-1537, 2002.

5. Battram DS, Graham TE, Richter EA, and Dela F. The effect of caffeine on glucose kinetics in humans--influence of adrenaline. $J$ Physiol 569: 347-355, 2005.

6. Boura-Halfon S, and Zick Y. Phosphorylation of IRS proteins, insulin action, and insulin resistance. Am J Physiol Endocrinol Metab 296: E581-591, 2009.

7. Corbould A, Zhao H, Mirzoeva S, Aird F, and Dunaif A. Enhanced mitogenic signaling in skeletal muscle of women with polycystic ovary syndrome. Diabetes 55: 751-759, 2006. 
8. D'Alessandris C, Lauro R, Presta I, and Sesti G. C-reactive protein induces phosphorylation of insulin receptor substrate-1 on $\operatorname{Ser}^{307}$ and $\operatorname{Ser}^{612}$ in L6 myocytes, thereby impairing the insulin signalling pathway that promotes glucose transport. Diabetologia 50: 840-849, 2007.

9. de Alvaro C, Teruel T, Hernandez R, and Lorenzo M. Tumor necrosis factor alpha produces insulin resistance in skeletal muscle by activation of inhibitor кB kinase in a p38 MAPK-dependent manner. J Biol Chem 279: 17070-17078, 2004.

10. DeFronzo RA. The triumvirate: beta-cell, muscle, liver. A collusion responsible for NIDDM. Diabetes 37: 667-687, 1988.

11. Egawa T, Hamada T, Kameda N, Karaike K, Ma X, Masuda S, Iwanaka N, and Hayashi T. Caffeine acutely activates 5'adenosine monophosphate-activated protein kinase and increases insulin-independent glucose transport in rat skeletal muscles. Metabolism 58: 1609-1617, 2009.

12. Egawa T, Hamada T, Ma X, Karaike K, Kameda N, Masuda S, Iwanaka N, and Hayashi T. Caffeine activates preferentially $\alpha 1$-isoform of 5'AMP-activated protein kinase in rat skeletal muscle. Acta Physiol (Oxf) 201: 227-238, 2011.

13. Esposito DL, Li Y, Cama A, and Quon MJ. Tyr ${ }^{612}$ and $\mathrm{Tyr}^{632}$ in human insulin receptor substrate-1 are important for full activation of insulin-stimulated phosphatidylinositol 3-kinase activity and translocation of GLUT4 in adipose cells. Endocrinology 142: 2833-2840, 2001. 
14. Foukas LC, Daniele N, Ktori C, Anderson KE, Jensen J, and Shepherd

PR. Direct effects of caffeine and theophylline on p110 $\delta$ and other phosphoinositide 3-kinases. Differential effects on lipid kinase and protein kinase activities. J Biol Chem 277: 37124-37130, 2002.

15. Fredholm BB. Are methylxanthine effects due to antagonism of endogenous adenosine? Trends in Pharmacological Sciences 1: 129-132, 1980.

16. Gao Z, Hwang D, Bataille F, Lefevre M, York D, Quon MJ, and Ye J. Serine phosphorylation of insulin receptor substrate 1 by inhibitor $\kappa \mathrm{B}$ kinase complex. J Biol Chem 277: 48115-48121, 2002.

17. Greer F, Hudson R, Ross R, and Graham T. Caffeine ingestion decreases glucose disposal during a hyperinsulinemic-euglycemic clamp in sedentary humans. Diabetes 50: 2349-2354, 2001.

18. Gual P, Le Marchand-Brustel Y, and Tanti JF. Positive and negative regulation of insulin signaling through IRS-1 phosphorylation. Biochimie 87: 99-109, 2005.

19. Harrington LS, Findlay GM, Gray A, Tolkacheva T, Wigfield S, Rebholz H, Barnett J, Leslie NR, Cheng S, Shepherd PR, Gout I, Downes CP, and Lamb RF. The TSC1-2 tumor suppressor controls insulin-PI3K signaling via regulation of IRS proteins. The Journal of cell biology 166: 213-223, 2004.

20. Hayashi T, Hirshman MF, Kurth EJ, Winder WW, and Goodyear LJ. Evidence for 5' AMP-activated protein kinase mediation of the effect of muscle 
contraction on glucose transport. Diabetes 47: 1369-1373, 1998.

21. Hiratani K, Haruta T, Tani A, Kawahara J, Usui I, and Kobayashi M. Roles of mTOR and JNK in serine phosphorylation, translocation, and degradation of IRS-1. Biochemical and biophysical research communications 335: 836-842, 2005.

22. Hirosumi J, Tuncman G, Chang L, Görgun CZ, Uysal KT, Maeda K, Karin M, and Hotamisligil GS. A central role for JNK in obesity and insulin resistance. Nature 420: 333-336, 2002.

23. Horike N, Takemori H, Katoh Y, Doi J, Min L, Asano T, Sun XJ, Yamamoto H, Kasayama S, Muraoka M, Nonaka Y, and Okamoto $M$. Adipose-specific expression, phosphorylation of $\mathrm{Ser}^{794}$ in insulin receptor substrate-1, and activation in diabetic animals of salt-inducible kinase-2. J Biol Chem 278: 18440-18447, 2003.

24. Iwanaka N, Egawa T, Satoubu N, Karaike K, Ma X, Masuda S, and Hayashi T. Leucine modulates contraction- and insulin-stimulated glucose transport and upstream signaling events in rat skeletal muscle. J Appl Physiol 108: 274-282, 2010.

25. Jakobsen SN, Hardie DG, Morrice N, and Tornqvist HE. 5'-AMP-activated protein kinase phosphorylates IRS-1 on Ser-789 in mouse C2C12 myotubes in response to 5-aminoimidazole-4-carboxamide riboside. $J$ Biol Chem 276: 46912-46916, 2001. 
26. Jensen TE, Rose AJ, Hellsten Y, Wojtaszewski JF, and Richter EA. Caffeine-induced $\mathrm{Ca}^{2+}$ release increases AMPK-dependent glucose uptake in rodent soleus muscle. Am J Physiol Endocrinol Metab 293: E286-292, 2007.

27. Keijzers GB, De Galan BE, Tack CJ, and Smits P. Caffeine can decrease insulin sensitivity in humans. Diabetes Care 25: 364-369, 2002.

28. Kolnes AJ, Ingvaldsen A, Bolling A, Stuenaes JT, Kreft M, Zorec R, Shepherd PR, and Jensen J. Caffeine and theophylline block insulin-stimulated glucose uptake and PKB phosphorylation in rat skeletal muscles. Acta Physiol (Oxf) 200: 65-74, 2010.

29. Lau C, Wang X, Song L, North M, Wiehler S, Proud D, and Chow CW. Syk associates with clathrin and mediates phosphatidylinositol 3-kinase activation during human rhinovirus internalization. J Immunol 180: 870-880, 2008.

30. Lee S, Hudson R, Kilpatrick K, Graham TE, and Ross R. Caffeine ingestion is associated with reductions in glucose uptake independent of obesity and type 2 diabetes before and after exercise training. Diabetes Care 28: 566-572, 2005.

31. Lelo A, Miners JO, Robson R, and Birkett DJ. Assessment of caffeine exposure: caffeine content of beverages, caffeine intake, and plasma concentrations of methylxanthines. Clin Pharmacol Ther 39: 54-59, 1986.

32. Moon MK, Lee YJ, Kim JS, Kang DG, and Lee HS. Effect of caffeic acid on tumor necrosis factor-alpha-induced vascular inflammation in human umbilical vein endothelial cells. Biological \& pharmaceutical bulletin 32: 
1371-1377, 2009.

33. Morino K, Petersen KF, Dufour S, Befroy D, Frattini J, Shatzkes N, Neschen S, White MF, Bilz S, Sono S, Pypaert M, and Shulman GI. Reduced mitochondrial density and increased IRS-1 serine phosphorylation in muscle of insulin-resistant offspring of type 2 diabetic parents. J Clin Invest 115: 3587-3593, 2005.

34. Qiao LY, Zhande R, Jetton TL, Zhou G, and Sun XJ. In vivo phosphorylation of insulin receptor substrate 1 at serine 789 by a novel serine kinase in insulin-resistant rodents. J Biol Chem 277: 26530-26539, 2002.

35. Shoelson SE, Lee J, and Yuan M. Inflammation and the IKK $\beta / \mathrm{I} \kappa \mathrm{B} / \mathrm{NF}-\kappa \mathrm{B}$ axis in obesity- and diet-induced insulin resistance. Int J Obes Relat Metab Disord 27 Suppl 3: S49-52, 2003.

36. Taniguchi CM, Emanuelli B, and Kahn CR. Critical nodes in signalling pathways: insights into insulin action. Nat Rev Mol Cell Biol 7: 85-96, 2006.

37. Tanti JF, and Jager J. Cellular mechanisms of insulin resistance: role of stress-regulated serine kinases and insulin receptor substrates (IRS) serine phosphorylation. Curr Opin Pharmacol 9: 753-762, 2009.

38. Thong FS, Derave W, Kiens B, Graham TE, Urso B, Wojtaszewski JF, Hansen BF, and Richter EA. Caffeine-induced impairment of insulin action but not insulin signaling in human skeletal muscle is reduced by exercise. Diabetes 51: 583-590, 2002. 
39. Toyoda T, Hayashi T, Miyamoto L, Yonemitsu S, Nakano M, Tanaka S, Ebihara K, Masuzaki H, Hosoda K, Inoue G, Otaka A, Sato K, Fushiki T, and Nakao K. Possible involvement of the $\alpha 1$ isoform of 5'AMP-activated protein kinase in oxidative stress-stimulated glucose transport in skeletal muscle. Am J Physiol Endocrinol Metab 287: E166-173, 2004.

40. Tremblay F, Krebs M, Dombrowski L, Brehm A, Bernroider E, Roth E, Nowotny P, Waldhausl W, Marette A, and Roden M. Overactivation of S6 kinase 1 as a cause of human insulin resistance during increased amino acid availability. Diabetes 54: 2674-2684, 2005.

41. Tzatsos A, and Tsichlis PN. Energy depletion inhibits phosphatidylinositol 3-kinase/Akt signaling and induces apoptosis via AMP-activated protein kinase-dependent phosphorylation of IRS-1 at Ser-794. J Biol Chem 282: 18069-18082, 2007.

42. Um SH, Frigerio F, Watanabe M, Picard F, Joaquin M, Sticker M, Fumagalli S, Allegrini PR, Kozma SC, Auwerx J, and Thomas G. Absence of S6K1 protects against age- and diet-induced obesity while enhancing insulin sensitivity. Nature 431: 200-205, 2004.

43. Youn JH, Gulve EA, and Holloszy JO. Calcium stimulates glucose transport in skeletal muscle by a pathway independent of contraction. Am J Physiol 260: C555-561, 1991.

44. Young DA, Uhl JJ, Cartee GD, and Holloszy JO. Activation of glucose transport in muscle by prolonged exposure to insulin. Effects of glucose and insulin 
concentrations. J Biol Chem 261: 16049-16053, 1986.

45. Yu C, Chen Y, Cline GW, Zhang D, Zong H, Wang Y, Bergeron R, Kim JK, Cushman SW, Cooney GJ, Atcheson B, White MF, Kraegen EW, and Shulman GI. Mechanism by which fatty acids inhibit insulin activation of insulin receptor substrate-1 (IRS-1)-associated phosphatidylinositol 3-kinase activity in muscle. J Biol Chem 277: 50230-50236, 2002. 


\section{LEGENDS TO FIGURES}

Figure 1

The dose- and time-dependent effects of caffeine on IRS-1 $\mathrm{Tyr}^{612}$ phosphorylation $\left(\mathrm{p}-\mathrm{Tyr}^{612}\right)$ in incubated rat epitrochlearis muscle. (A) Isolated muscle was preincubated for $40 \mathrm{~min}$ and incubated in the presence of caffeine at indicated concentrations for $15 \mathrm{~min}$. Muscle was then incubated with or without $1 \mu \mathrm{M}$ insulin in the presence of caffeine at indicated concentrations for $15 \mathrm{~min}$. (B) Isolated muscle was preincubated for $40 \mathrm{~min}$ and incubated with $3 \mathrm{mM}$ caffeine for indicated times. Muscle was then incubated with $1 \mu \mathrm{M}$ insulin in the presence of caffeine at indicated concentrations for $15 \mathrm{~min}$. Control muscle (open bar) was incubated without caffeine or insulin for $30 \mathrm{~min}$. The tissue lysate was subjected to western blot analysis. Fold increases are expressed relative to the level of signal in the control muscles. Representative immunoblots are shown. Values are mean $\pm \mathrm{SE} ; \mathrm{n}=$

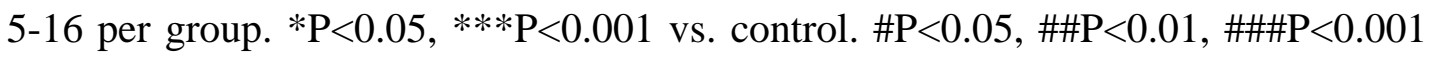
vs. insulin alone.

Figure 2

The effect of caffeine on (A) IR $\beta$ Tyr ${ }^{1158 / 1162 / 1163}$ phosphorylation (p-IR $\beta$ ), (B) PI3K p85 Tyr ${ }^{458}$ phosphorylation (p-PI3K p85), (C) Akt Ser ${ }^{473}$ phosphorylation (p-Akt), (D) GSK3 $\beta$ Ser$^{9}$ phosphorylation (p-GSK3 $\beta$ ), and (E) 3-O-methyl-D-glucose (3MG) transport activity in incubated rat epitrochlearis muscle. Isolated muscle was preincubated for $40 \mathrm{~min}$ and incubated for $15 \mathrm{~min}$ in the absence or presence of 3 $\mathrm{mM}$ caffeine. Muscle was then incubated with or without $1 \mu \mathrm{M}$ insulin in the 
absence or presence of $3 \mathrm{mM}$ caffeine for $15 \mathrm{~min}$. The muscle was subjected to western blot analysis (A-D) or 3MG transport assay (E). Fold increases are expressed relative to the level of signal in the control muscles. Representative immunoblots are shown. Values are mean $\pm \mathrm{SE} ; \mathrm{n}=5$ - 11 per group. ${ }^{*} \mathrm{P}<0.05$, $* * \mathrm{P}<0.01, * * * \mathrm{P}<0.001$

Figure 3

The effect of caffeine on (A) IRS-1 Ser ${ }^{307}$ phosphorylation (p-Ser ${ }^{307}$ ), (B) IKK Ser ${ }^{176 / 180}$ phosphorylation (p-IKK), (C) JNK Thr ${ }^{183} / \mathrm{Tyr}^{185}$ phosphorylation (p-JNK), (D) ERK Thr' ${ }^{202} / \mathrm{Tyr}^{204}$ phosphorylation (p-ERK), and (E) p38 MAPK $\mathrm{Thr}^{180} / \mathrm{Tyr}^{182}$ phosphorylation (p-p38 MAPK) in incubated rat epitrochlearis muscle. Isolated muscle was preincubated for $40 \mathrm{~min}$ and incubated for $15 \mathrm{~min}$ in the absence or presence of $3 \mathrm{mM}$ caffeine. Muscle was then incubated with or without $1 \mu \mathrm{M}$ insulin in the absence or presence of $3 \mathrm{mM}$ caffeine for $15 \mathrm{~min}$. The tissue lysate (B-E) and immnoprecipitate by anti IRS-1 antibody (IP:IRS-1) (A) was subjected to western blot analysis. Fold increases are expressed relative to the level of signal in the control muscles. Representative immunoblots are shown. Values are mean $\pm \mathrm{SE} ; \mathrm{n}=$ 5-10 per group. $* \mathrm{P}<0.05$, $* * \mathrm{P}<0.01, * * * \mathrm{P}<0.001$.

Figure 4

The inhibitory effect of caffeine-induced (A) IRS-1 Ser ${ }^{307}$ phosphorylation (p-Ser ${ }^{307}$ ), and (B) IKK Ser ${ }^{176 / 180}$ phosphorylation (p-IKK) by caffeic acid on (C) IRS-1 Tyr ${ }^{612}$ phosphorylation (p-Tyr ${ }^{612}$ ), (D) Akt phosphorylation (p-Akt), and (E) 3MG transport. Isolated muscle was preincubated for $40 \mathrm{~min}$ and incubated for $15 \mathrm{~min}$ in the 
absence or presence of $3 \mathrm{mM}$ caffeine. Muscle was then incubated with or without 1 $\mu \mathrm{M}$ insulin in the absence or presence of $3 \mathrm{mM}$ caffeine for $15 \mathrm{~min}$. When present, 5 $\mathrm{mM}$ caffeic was added throughout the preincubation and incubation periods. The tissue lysate (B-D) and immnoprecipitate by anti IRS-1 antibody (IP:IRS-1) (A) was subjected to western blot analysis. Muscle was also subjected to 3MG transport assay (E). Fold increases are expressed relative to the level of signal in the control muscles. Representative immunoblots are shown. Values are mean \pm SE; $n=6$-8 per group. $* \mathrm{P}<0.05, * * * \mathrm{P}<0.001$.

Figure 5

The effect of caffeine on (A) IRS-1 Ser ${ }^{789}$ phosphorylation (p-Ser ${ }^{789}$ ), (B) AMPK Thr ${ }^{172}$ phosphorylation (p-AMPK), and (C) ACC Ser ${ }^{79}$ phosphorylation (p-ACC) in incubated rat epitrochlearis muscle. Isolated muscle was preincubated for $40 \mathrm{~min}$ and incubated for $15 \mathrm{~min}$ in the absence or presence of $3 \mathrm{mM}$ caffeine. Muscle was then incubated with or without $1 \mu \mathrm{M}$ insulin in the absence or presence of $3 \mathrm{mM}$ caffeine for $15 \mathrm{~min}$. The tissue lysate was subjected to western blot analysis. Fold increases are expressed relative to the level of signal in the control muscles. Representative immunoblots are shown. Values are mean $\pm \mathrm{SE}$; $\mathrm{n}=4-9$ per group. $* \mathrm{P}<0.05, * * * \mathrm{P}<0.001$.

Figure 6

The inhibitory effect of caffeine-induced (A) IRS-1 Ser ${ }^{789}$ phosphorylation (p-Ser ${ }^{789}$ ), and (B) AMPK Thr ${ }^{172}$ phosphorylation (p-AMPK) by dantrolene on (C) IRS-1 Tyr ${ }^{612}$ phosphorylation (p-Tyr ${ }^{612}$ ), (D) Akt phosphorylation (p-Akt), and (E) 3MG transport. 
Isolated muscle was preincubated for $40 \mathrm{~min}$ and incubated for $15 \mathrm{~min}$ in the absence or presence of $3 \mathrm{mM}$ caffeine. Muscle was then incubated with or without 1 $\mu \mathrm{M}$ insulin in the absence or presence of $3 \mathrm{mM}$ caffeine for $15 \mathrm{~min}$. When present, 5 $\mu \mathrm{M}$ dantrolene was added throughout the preincubation and incubation periods. The muscle was subjected to western blot analysis (A-D) or 3MG transport assay (E). Fold increases are expressed relative to the level of signal in the control muscles. Representative immunoblots are shown. Values are mean $\pm \mathrm{SE} ; \mathrm{n}=6-8$ per group. $* \mathrm{P}<0.05, * * * \mathrm{P}<0.001$.

Figure 7

The effect of caffeine on (A) IRS-1 Ser ${ }^{636 / 639}$ phosphorylation (p-Ser ${ }^{636 / 639}$ ), (B) mTOR Ser ${ }^{2448}$ phosphorylation (p-mTOR), and (C) p70S6K Thr ${ }^{389}$ phosphorylation (p-p70S6K) in incubated rat epitrochlearis muscle. Isolated muscle was preincubated for $40 \mathrm{~min}$ and incubated for $15 \mathrm{~min}$ in the absence or presence of caffeine. Muscle was then incubated with or without $1 \mu \mathrm{M}$ insulin in the absence or presence of $3 \mathrm{mM}$ caffeine for $15 \mathrm{~min}$. The tissue lysate was subjected to western blot analysis. Fold increases are expressed relative to the level of signal in the control muscles. Representative immunoblots are shown. Values are mean \pm SE; $n=8$-13 per group. $* * \mathrm{P}<0.01, * * * \mathrm{P}<0.001$.

\section{Figure 8}

The effect of caffeine on (A) IRS-1 $\mathrm{Tyr}^{612}$ phosphorylation (p-Tyr ${ }^{612}$ ) and (B) Akt phosphorylation (p-Akt) in rat epitrochlearis muscle in vivo. Sixty min after intravenous injection of caffeine $(5 \mathrm{mg} / \mathrm{kg})$ or saline, insulin $(100 \mathrm{mU} / \mathrm{kg}$ body 
weight) or saline was injected intravenously. One min after insulin or saline injection epitrochlearis muscle was dissected, and tissue lysate was subjected to western blot analysis. Fold increases are expressed relative to the level of signal in the control muscles. Representative immunoblots are shown. Values are mean $\pm \mathrm{SE}$; $n=6$-15 per group. ${ }^{* *} \mathrm{P}<0.01,{ }^{* * *} \mathrm{P}<0.001$. 


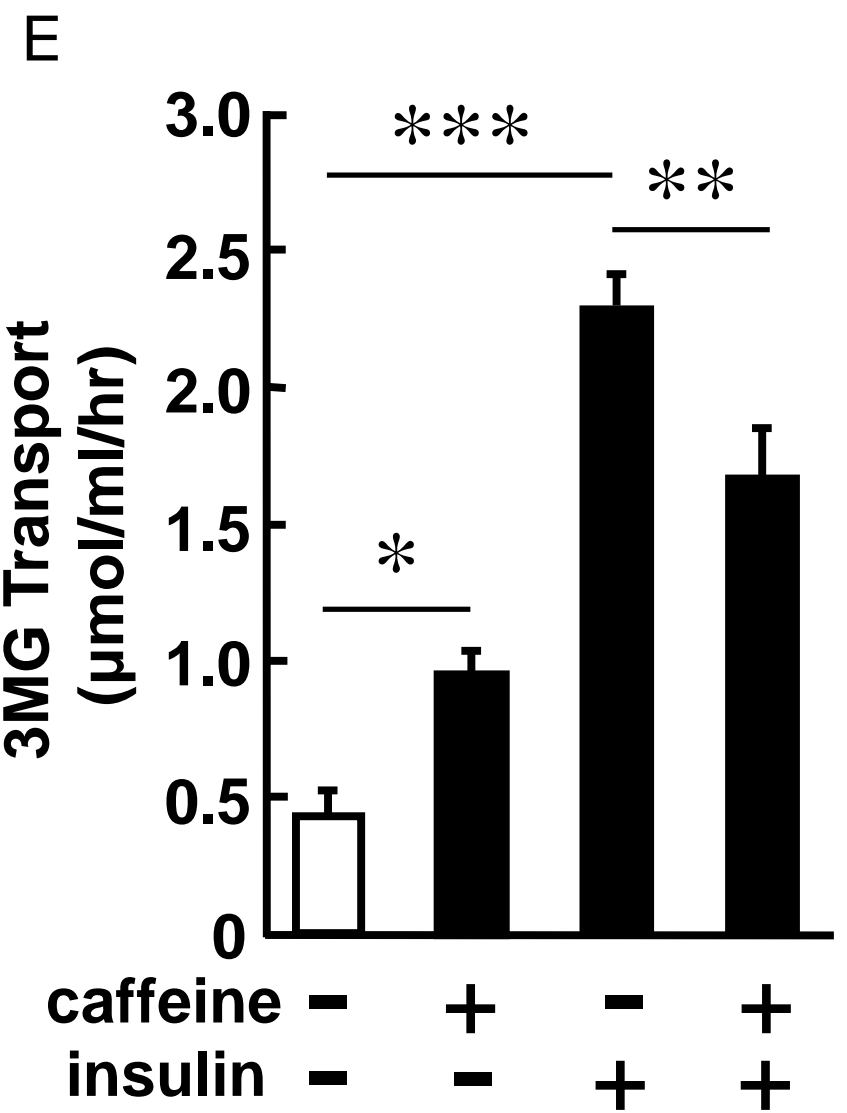


A

IP:IRS-1

$$
\begin{gathered}
\text { p-Ser } \\
\text { IRS-1 }
\end{gathered}
$$

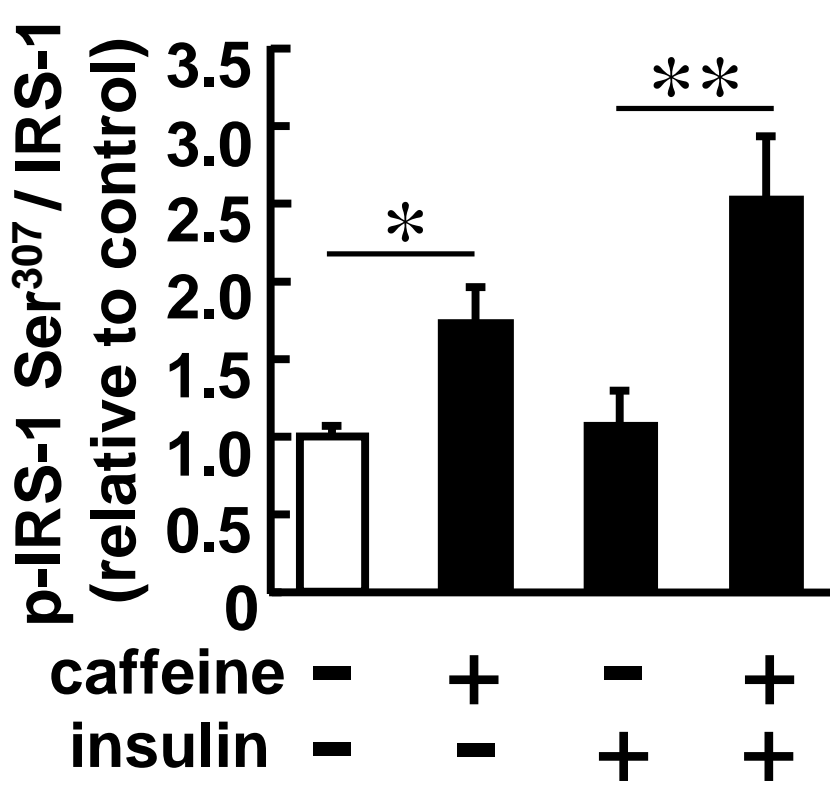

Figure. 3 


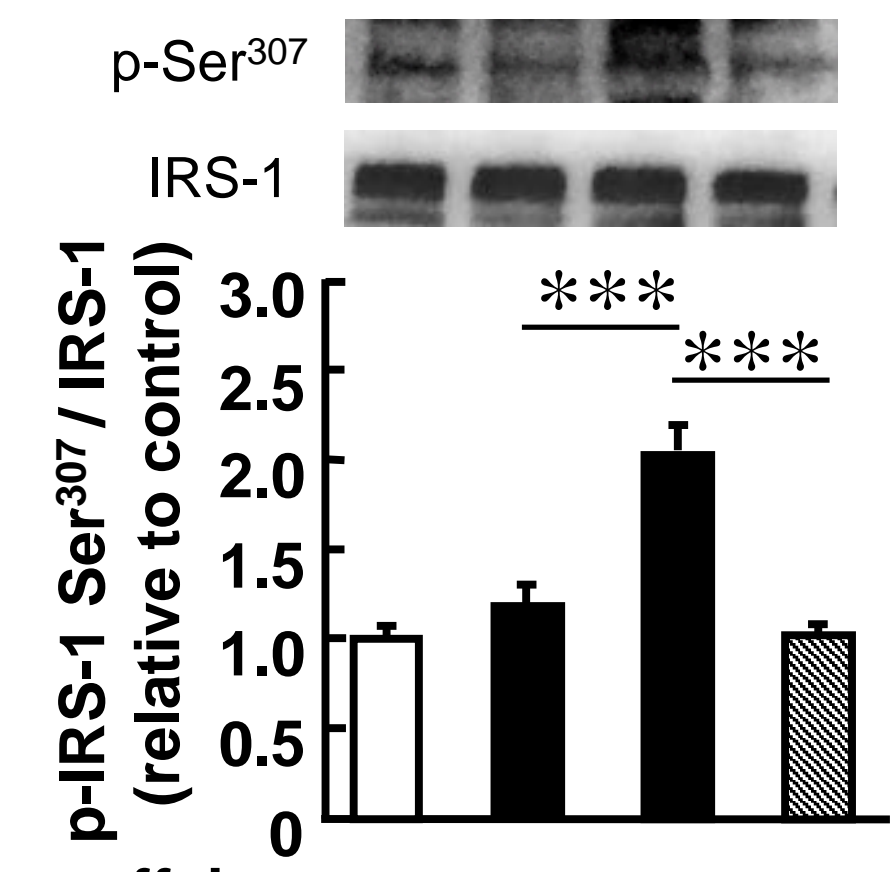

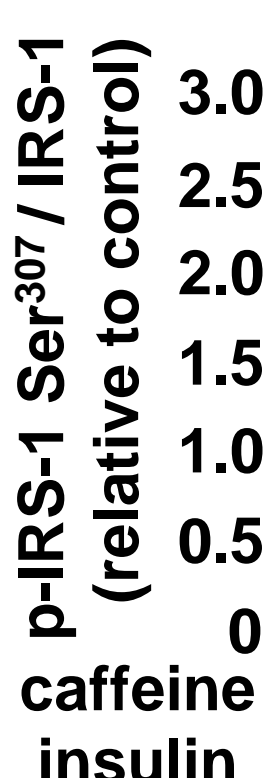

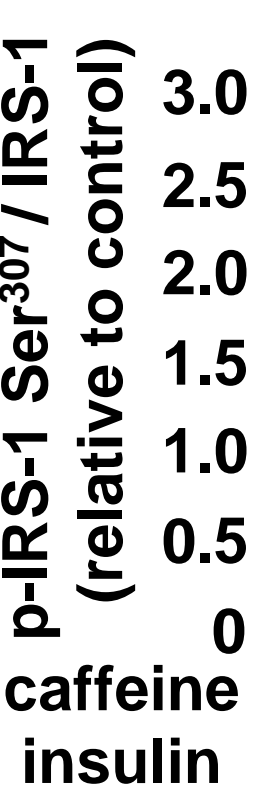
ca

p-Tyr 612 $\begin{array}{lll}- & + & + \\ + & + & +\end{array}$

IRS-1

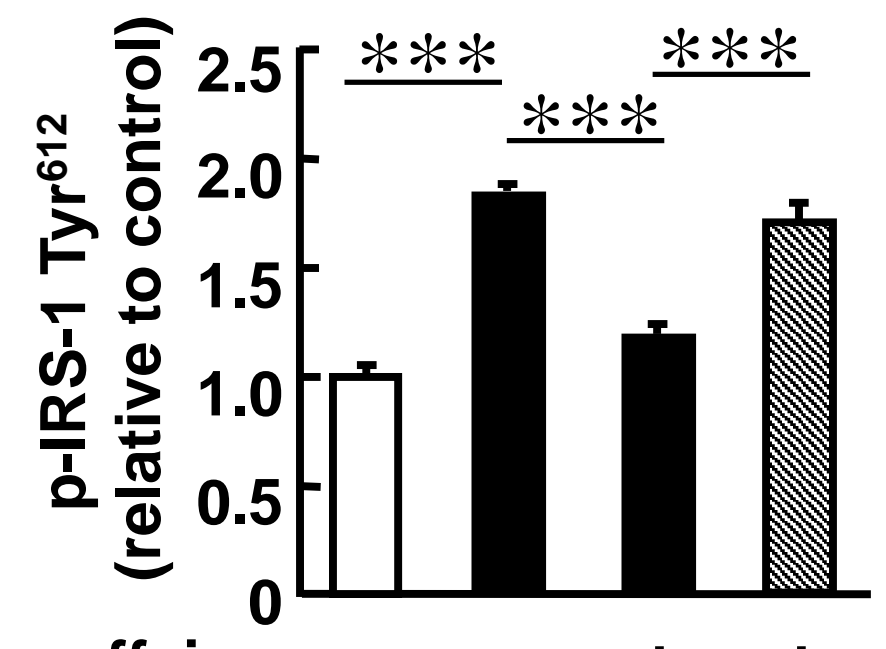

\section{ca} $+$

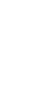

$-+t$ $-\quad-$

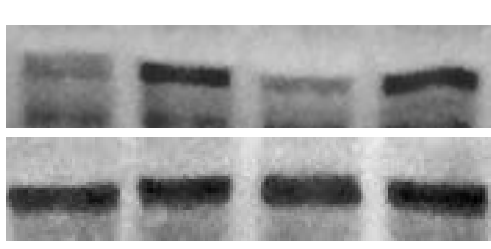
c

Figure. 4 


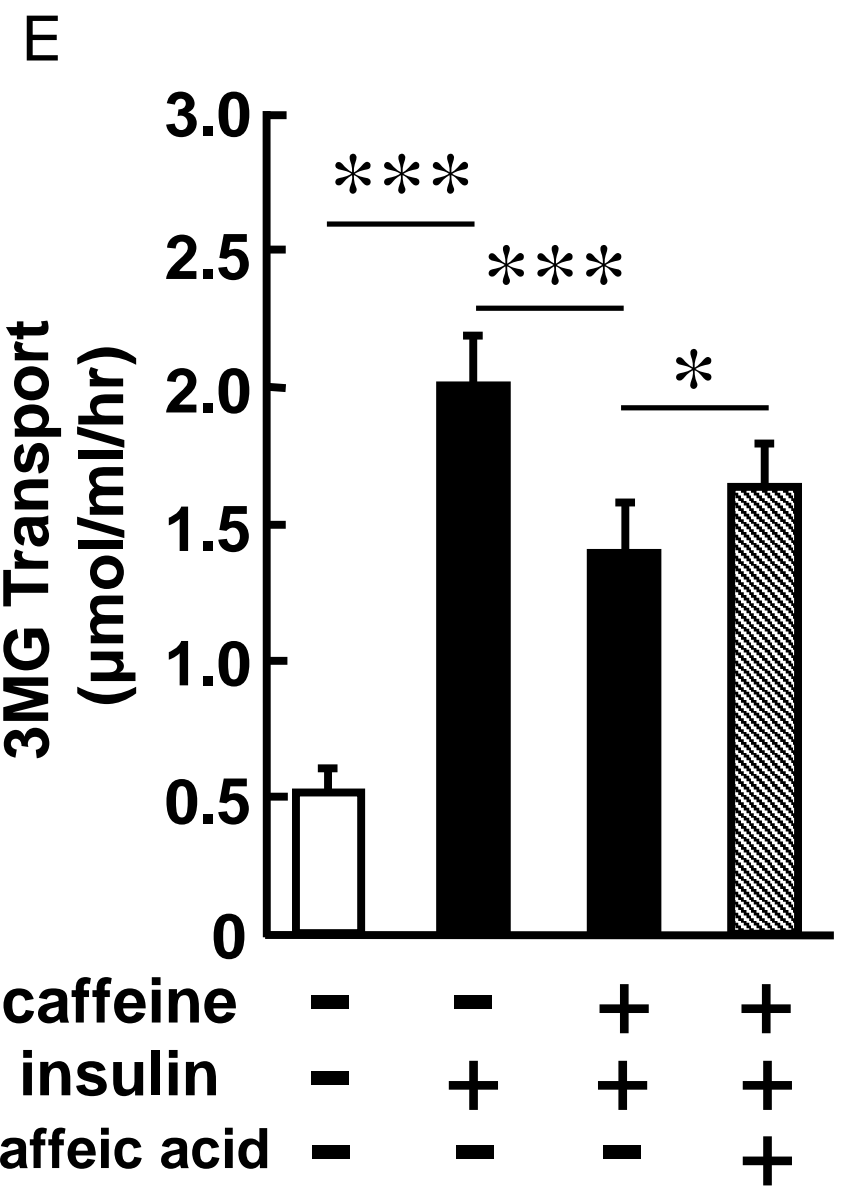


p-Ser ${ }^{789}$

IRS-1

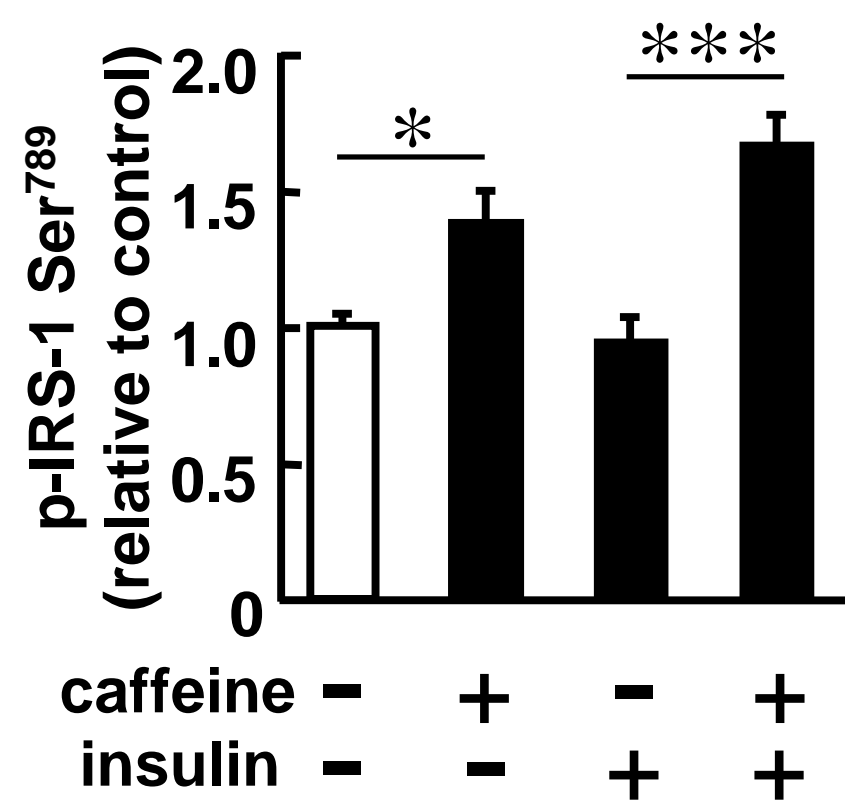

B

p-AMPK

C

AMPKa

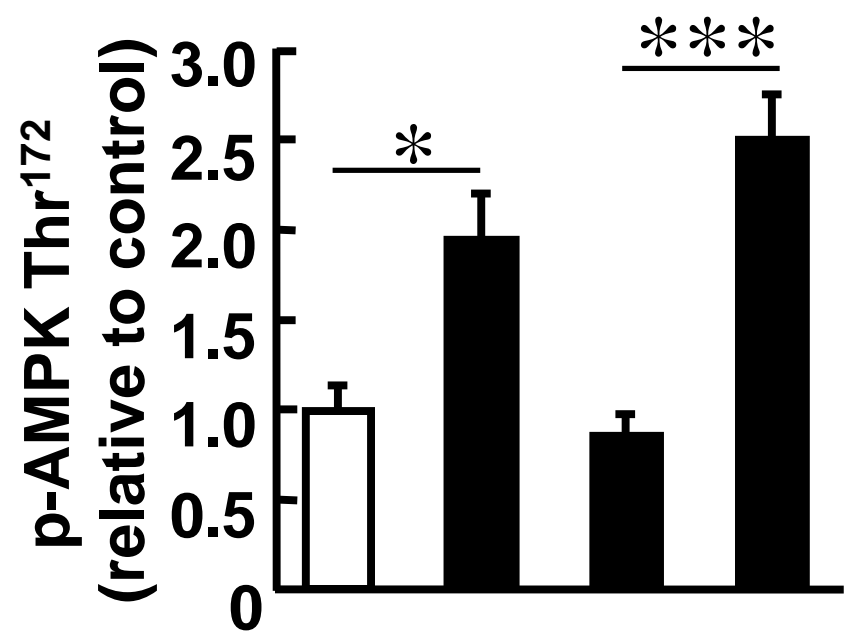

ca

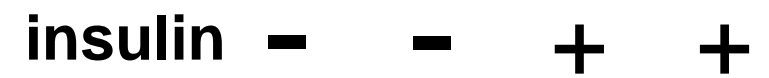

p-ACC

ACC

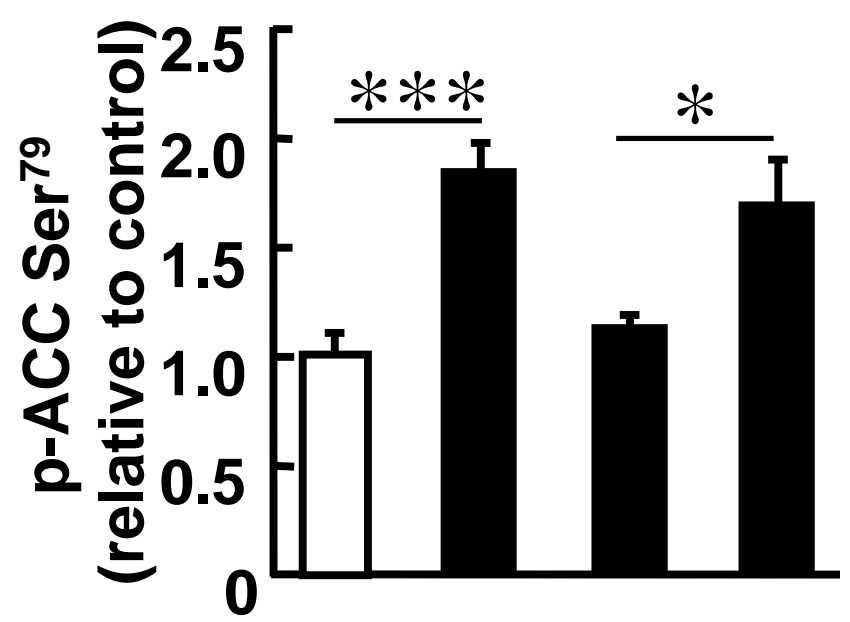

caffeine $-\quad+\quad-\quad+$ insulin $-\quad++$

Figure. 5 
IRS-1

AMPKa

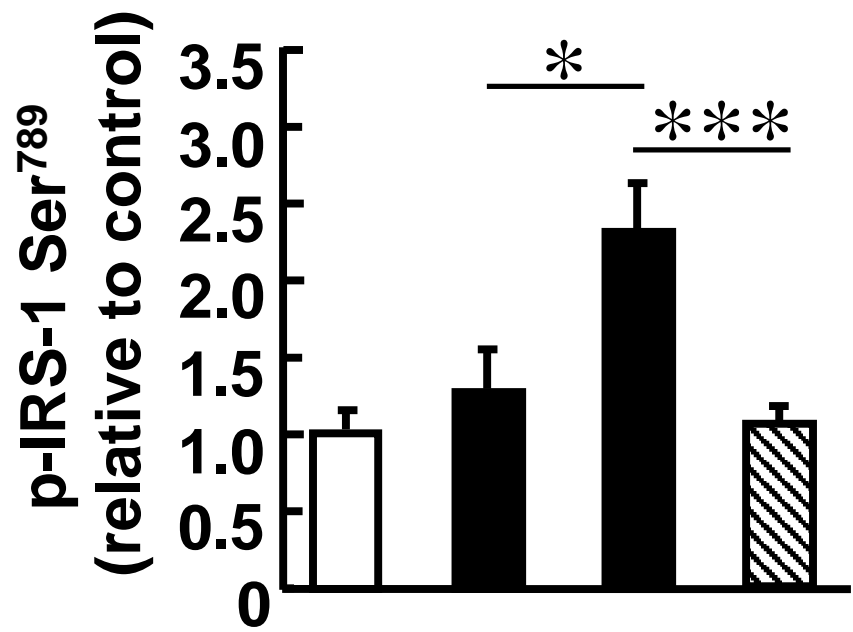

caffeine $\quad-\quad+\quad+$ insulin -+++ dantrolene $-\quad-\quad-\quad+$

C

p-Tyr 612

D

IRS-1

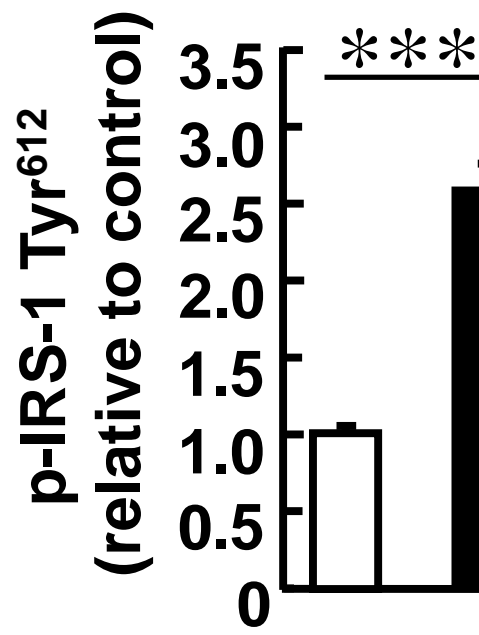

caffeine insulin -++

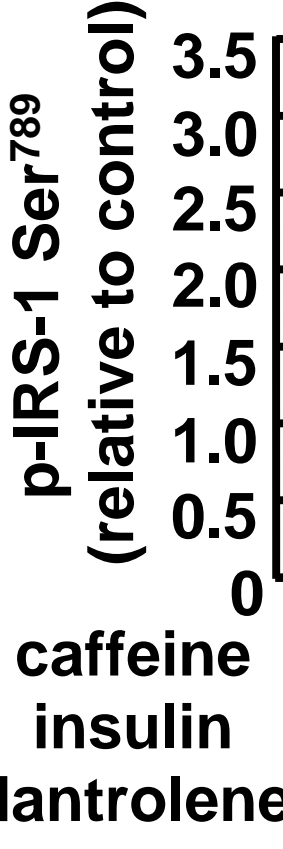
Akt

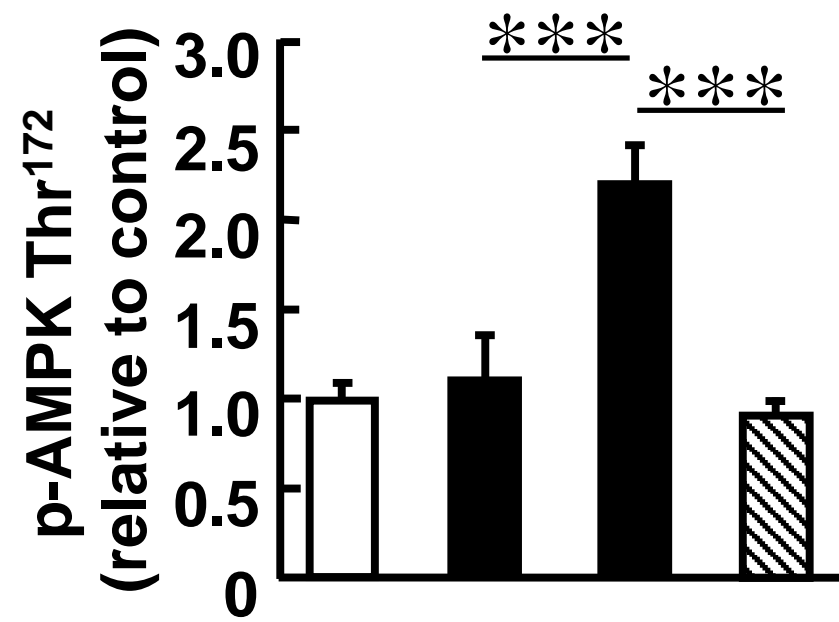

caffeine $-\quad-\quad++$ insulin -+++ dantrolene - $\quad-\quad+$
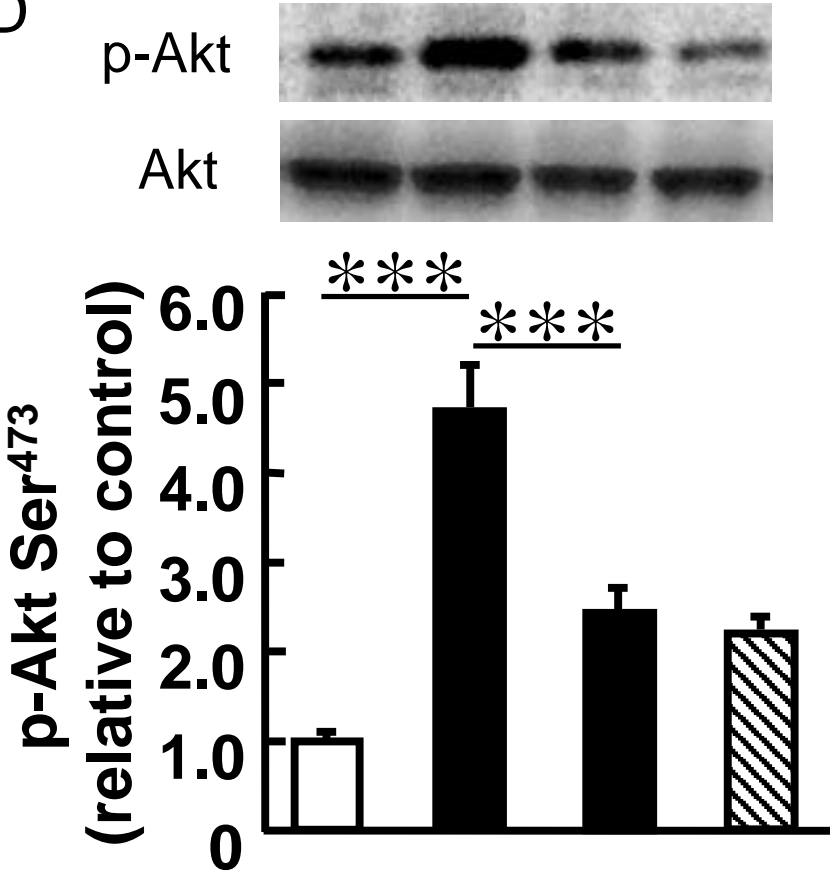

caffeine $\quad-\quad-\quad+\quad+$ insulin $-++t$ dantrolene - $\quad-\quad-\quad+$

Figure. 6 


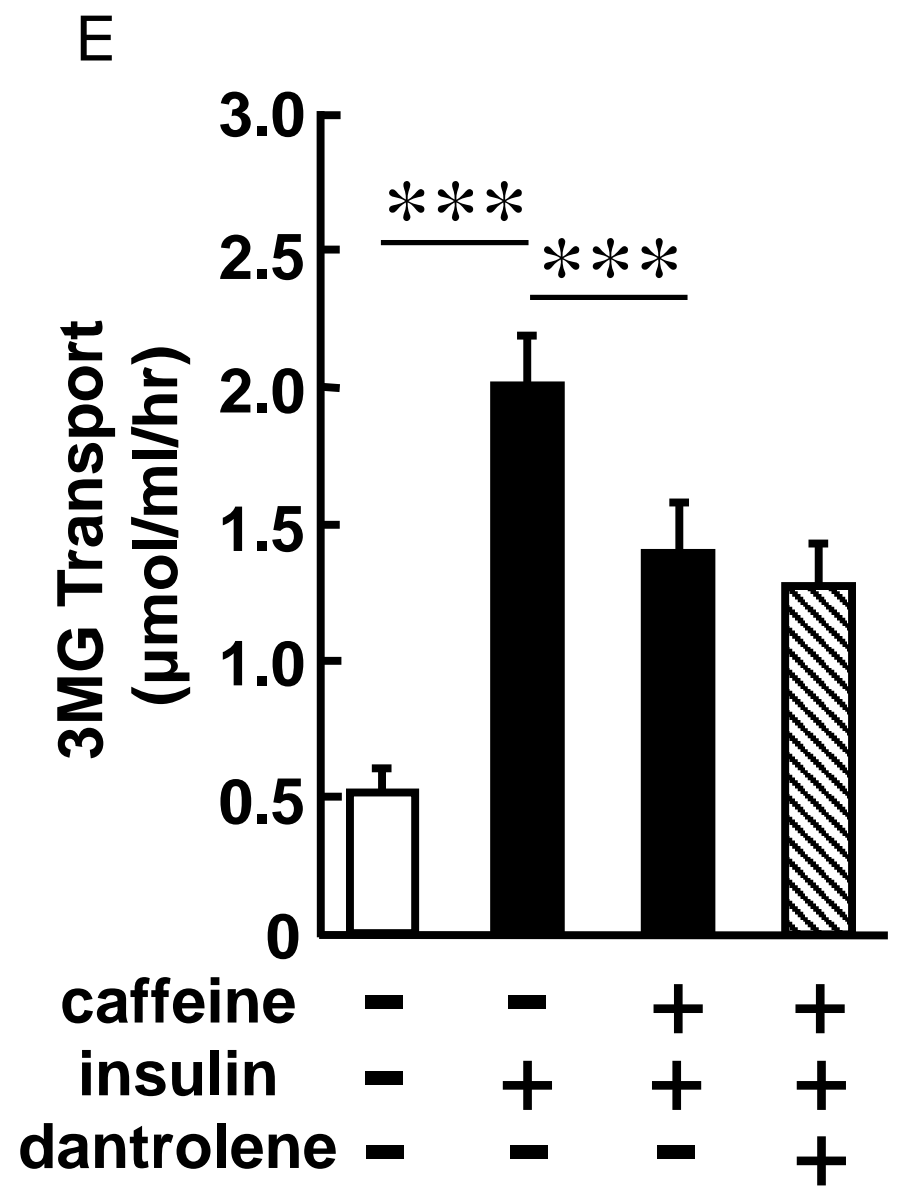


p-Ser $636 / 639$

IRS-1

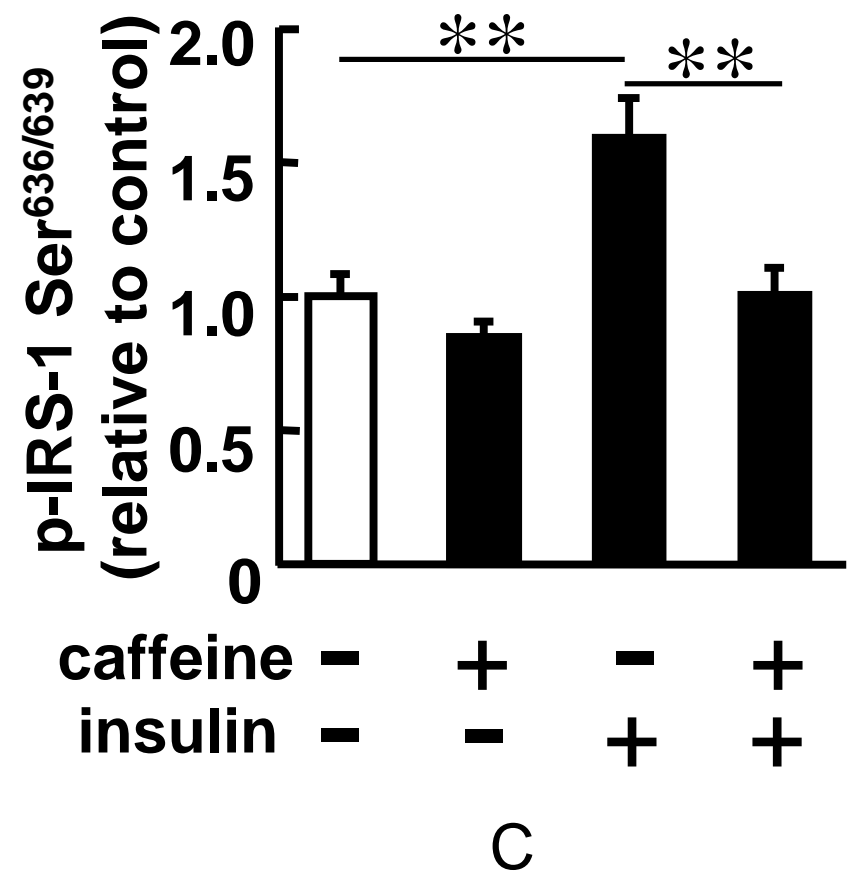

p-mTOR

mTOR
p-p70S6K

p70S6K

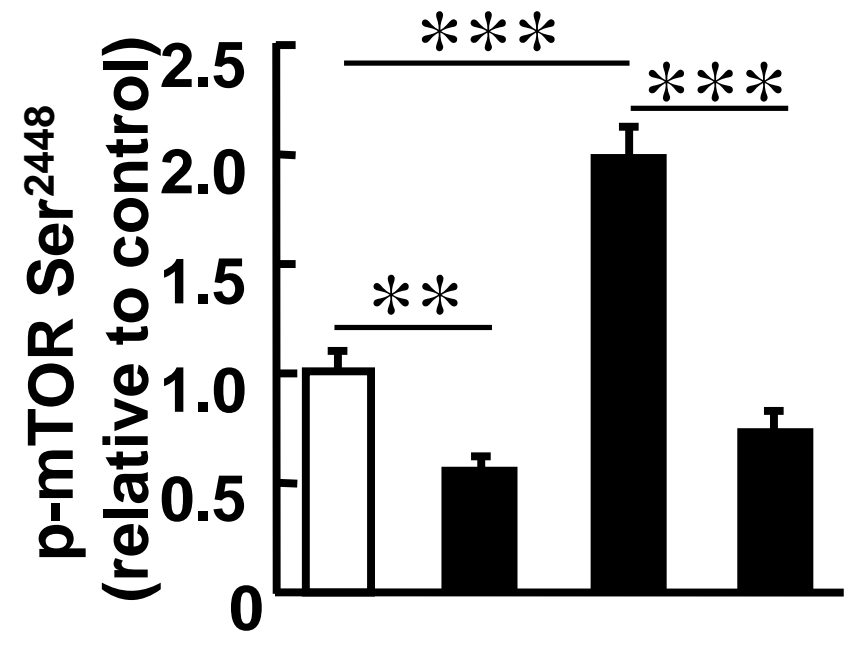
insulin $-\quad+\quad+$

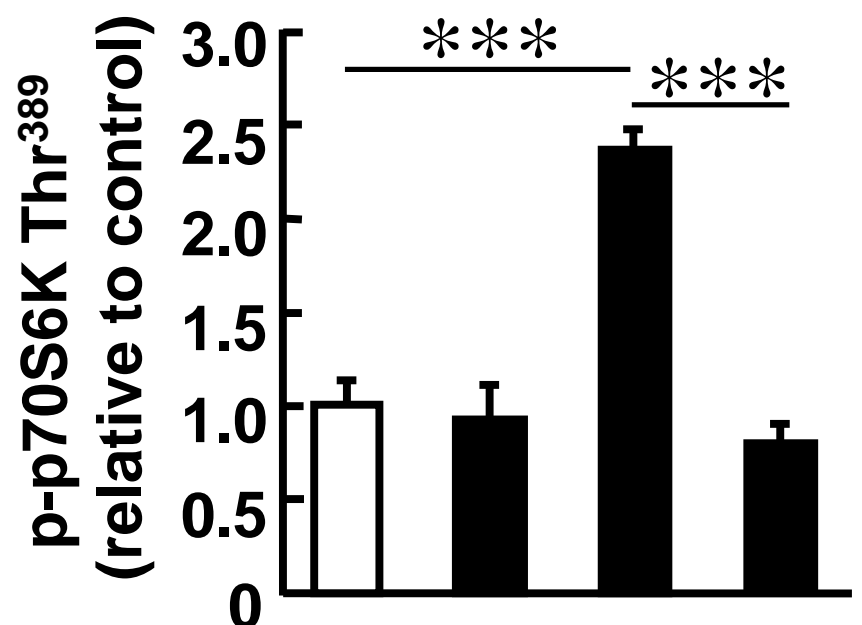

caffeine $-\quad+\quad-\quad+$ insulin $-\quad-+t$

Figure. 7 
A

p-Tyr 612

IRS-1

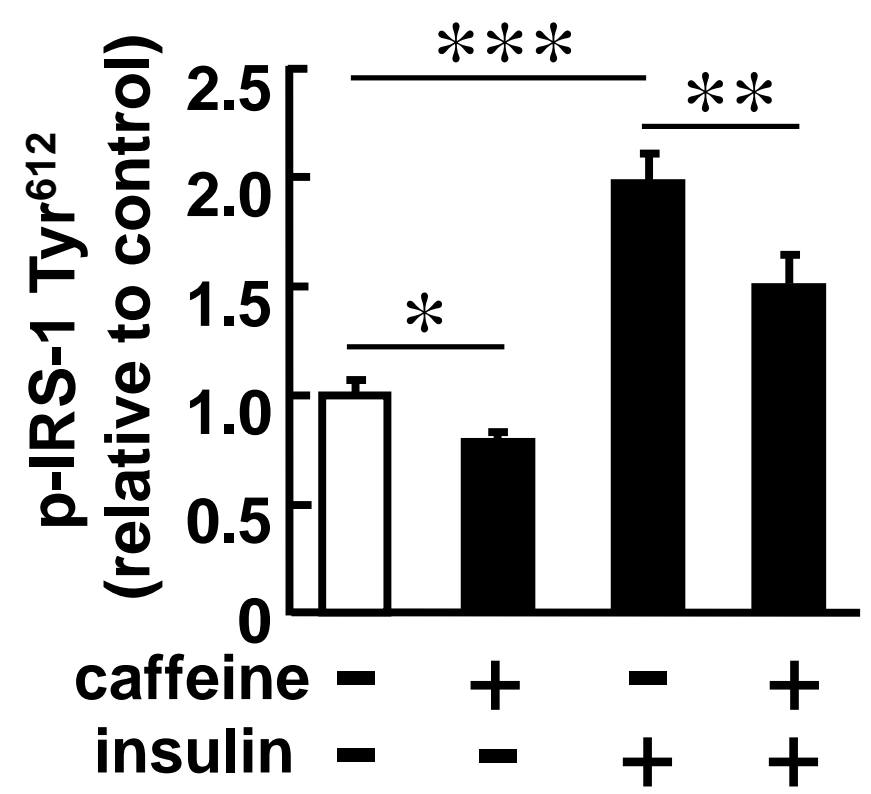

B

p-Akt

Akt

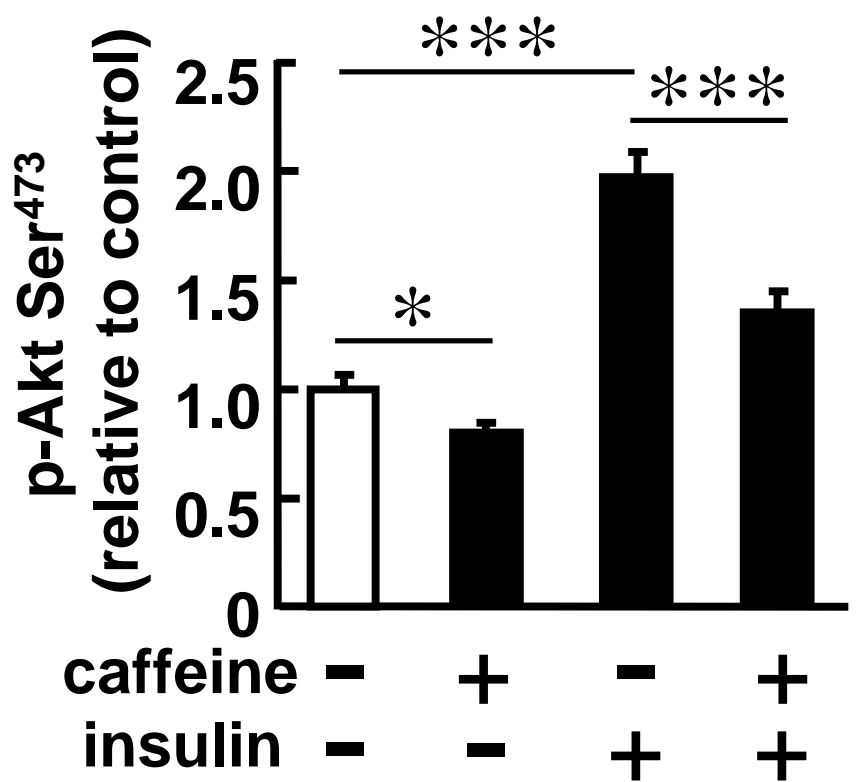

Figure. 8 